\title{
Properties of innovative renders on a lime basis for the renovation of historical buildings
}

\author{
E. Vejmelková ${ }^{1}, \mathrm{R}$. Pernicová ${ }^{1}, \mathrm{R}$. Sovják ${ }^{2} \&$ R. Černý \\ ${ }^{1}$ Department of Materials Engineering and Chemistry, \\ Faculty of Civil Engineering, Czech Technical University in Prague, \\ Czech Republic \\ ${ }^{2}$ Experimental Center, Faculty of Civil Engineering, \\ Czech Technical University in Prague, Czech Republic
}

\begin{abstract}
Mechanical and hygric properties, namely compressive strength, bending strength, water sorptivity, moisture diffusivity and the water vapor diffusion coefficient, of two innovative lime plasters with pozzolanic admixtures (metakaolin, metashale) and two commercial renovation plasters are studied in this paper. Reference measurements with common lime plaster are done as well. Experimental results show that the analyzed lime-pozzolana plasters are suitable for an application in reconstruction of historical buildings. Their mechanical properties are superior to lime plaster and better or similar to commercial renovation plasters. Their hygric properties are similar to lime plaster or slightly better and comparable with commercial plasters.
\end{abstract}

Keywords: lime plasters, metakaolin, metashale, mechanical properties, hygric properties.

\section{Introduction}

In the reconstruction of historical buildings, such materials are required that are as close as possible to the original materials in their chemical composition and physical properties. However, for the exterior renders the original materials mostly cannot be replaced in an identical way because nowadays the technology of lime production achieves a very high level, so that very pure lime can be produced. In a comparison with lime produced in the past on imperfect devices, without sorting of the raw material and with ash matter present, the current lime 
has a different quality and different bonding properties. Current lime creates the solid structure by carbonation and the final product, calcium carbonate, has a lower strength than the products of hydraulic or pozzolanic hardening. In mortars and renders, this feature is eliminated by addition of Portland cement (often white cement). However, this method of modification of mechanical properties of mortars and renders is not preferred by cultural heritage authorities. Therefore, pozzolanic admixtures present a prospective material base that can possibly be used for the improvement of the mechanical properties of lime renders instead of cement (e.g. [1-3]). In this paper, metakaolin and metashale were chosen as pozzolanic additions to lime plasters.

\section{Materials}

The composition of the studied plasters is shown in Table $1(\mathrm{w} / \mathrm{b}$ is the water to binder ratio). They differed in the admixtures used for their preparation. Two of them contained pozzolana admixtures, namely metakaolin (P3) and metashale (P2). The other two were commercial renovation plasters (P4), (P5), their exact composition was not known. The fifth was reference lime plaster without admixtures (P1). Metashale and metakaolin were produced by České lupkové závody Inc., Nové Strašecí, CZ.

\section{Experimental methods}

\subsection{Basic physical properties}

Among the basic properties, the bulk density, matrix density and open porosity were measured using the water vacuum saturation method [4]. Each sample was dried in a drier to remove the majority of the physically bound water. After that, the samples were placed into the desiccator with deaired water. During three hours air was evacuated with a vacuum pump from the desiccator. The specimen was then kept under water for not less than 24 hours.

Table 1: $\quad$ The composition of the studied plasters.

\begin{tabular}{|l|l|l|l|l|l|}
\hline & $\begin{array}{l}\text { Lime } \\
{[\mathrm{kg}]}\end{array}$ & $\begin{array}{l}\text { Metakaolin } \\
{[\mathrm{kg}]}\end{array}$ & $\begin{array}{l}\text { Metashale } \\
{[\mathrm{kg}]}\end{array}$ & $\begin{array}{l}\text { Natural quartz and } \\
\text { basalt sand 0 to 4 mm } \\
{[\mathrm{kg}]}\end{array}$ & w/b \\
\hline P1 & 2.5 & - & - & 7.5 & 0.29 \\
\hline P2 & 2 & - & 0.5 & 7.5 & 0.22 \\
\hline P3 & 2 & 0.5 & - & 7.5 & 0.24 \\
\hline P4 & \multicolumn{6}{|l}{ Baumit - Commercial renovation plaster WTA } & 0.18 \\
\hline P5 & \multicolumn{6}{|l}{ Cemix - Commercial renovation plaster WTA } & 0.23 \\
\hline
\end{tabular}


From the mass of water saturated sample $m_{w}$ and the mass of the immersed water saturated sample $m_{a}$, the volume $V$ of the sample was determined using the equation

$$
\mathrm{V}=\frac{\mathrm{m}_{\mathrm{w}}-\mathrm{m}_{\mathrm{a}}}{\rho_{\mathrm{w}}}
$$

where $\rho_{w}$ is the density of water. The open porosity $\psi_{0}$, the bulk density $\rho$ and the matrix density $\rho_{\text {mat }}$ were calculated according to the equations

$$
\begin{gathered}
\psi_{0}=\frac{m_{w}-m_{d}}{V \rho_{w}} \\
\rho=\frac{m_{d}}{V} \\
\rho_{\text {mat }}=\frac{m_{d}}{V\left(1-\psi_{0}\right)}
\end{gathered}
$$

The measurement of basic parameters took place in a conditioned laboratory at the temperature of $22 \pm 1{ }^{\circ} \mathrm{C}$ and $25-30 \%$ relative humidity. Each result represents the average value from three to five measured values. In the experiment 6 samples of $50 \times 50 \times 25 \mathrm{~mm}$ were used.

\subsection{Mechanical properties}

The measurement of bending strength was done on $40 \times 40 \times 160 \mathrm{~mm}$ prisms. Every specimen was positioned in such a way that the sides that were horizontal during the preparation were in the vertical position during the test. The experiment was performed as a common three-point bending test using the WPM $50 \mathrm{kN}$ device. The distance of the supporting cylinders was $100 \mathrm{~mm}$. The bending strength was calculated according to the standard evaluation procedure. Compressive strength was determined on the halves of the specimens left over after the bending tests. The specimens were placed between the two plates of the WPM $100 \mathrm{kN}$ device in such a way that their lateral sides adjoining during the preparation to the vertical sides of the molds were in contact with the plates. In this way, the imprecision of the geometry on the upper cut off side was not affecting negatively the experiment. The compressive strength was calculated as the ratio of the ultimate force and load area.

\subsection{Water vapor transport properties}

The wet cup method and dry cup method were employed in the measurements of water vapor transport parameters [4]. In the dry cup method the sealed cup containing silica gel was placed in a controlled climatic chamber with $97 \%$ relative humidity and weighed periodically. For wet cup method sealed cup containing water was placed in an environment with the temperature of $25^{\circ} \mathrm{C}$ and 
relative humidity of $25 \%$. The measurements were done at $25^{\circ} \mathrm{C}$ in a period of two weeks. The steady state values of mass gain or mass loss determined by linear regression for the last five readings were used for the determination of water vapor transport properties.

The water vapor diffusion coefficient $D$ was calculated from the measured data according to the equation

$$
D=\frac{\Delta m \cdot d \cdot R \cdot T}{S \cdot \tau \cdot M \cdot \Delta p_{p}}
$$

where $D$ is the water vapor diffusion coefficient $\left[\mathrm{m}^{2} \mathrm{~s}^{-1}\right], \Delta m$ the amount of water vapor diffused through the sample $[\mathrm{kg}], d$ the sample thickness [m], $S$ the specimen surface $\left[\mathrm{m}^{2}\right], \tau$ the period of time corresponding to the transport of mass of water vapor $\Delta m[\mathrm{~s}], \Delta p_{p}$ the difference between partial water vapor pressure in the air under and above specific specimen surface $[\mathrm{Pa}], R$ the universal gas constant, $M$ the molar mass of water, $T$ the absolute temperature [K].

On the basis of the diffusion coefficient $D$, the water vapor diffusion permeability $\delta[\mathrm{s}]$ and water vapor diffusion resistance factor $\mu[-]$ were determined,

$$
\begin{gathered}
\delta=D \frac{M}{R T} \\
\mu=\frac{D_{a}}{D}
\end{gathered}
$$

where $D_{a}$ is the diffusion coefficient of water vapor in the air.

In the experimental work, 3 cylindrical specimens with the diameter $105 \mathrm{~mm}$ and thickness $20 \mathrm{~mm}$ were used.

\subsection{Water transport properties}

The water sorptivity was measured using a standard experimental setup. The specimen was water and vapor-proof insulated on four lateral sides and the face side was immersed 1-2 $\mathrm{mm}$ in the water, constant water level in tank was achieved by a Mariotte bottle with two capillary tubes. One of them, inside diameter $2 \mathrm{~mm}$, was ducked under the water level, the second one, inside diameter $5 \mathrm{~mm}$, was above the water level. The automatic balance allowed for recording the increase of mass. The water absorption coefficient $A\left[\mathrm{kgm}^{-2} \mathrm{~s}^{-1 / 2}\right]$ was then calculated using the formula

$$
\mathrm{i}=\mathrm{A} \cdot \sqrt{\mathrm{t}}
$$


where $i\left[\mathrm{~kg} / \mathrm{m}^{2}\right]$ is the cumulative water absorption, $t$ is the time from the beginning of the suction experiment. The water absorption coefficient was then used for the calculation of the apparent moisture diffusivity in the form [5]

$$
\kappa_{a p p} \approx\left(\frac{A}{w_{c}}\right)^{2}
$$

where $w_{c}\left[\mathrm{kgm}^{-3}\right]$ is the saturated moisture content.

In the experimental work 5 specimens of $50 \times 50 \times 20 \mathrm{~mm}$ were used.

\section{Experimental results and discussion}

\subsection{Basic physical properties}

Table 2 shows that the lime plasters P2, P3 achieved slightly lower values of bulk density (about 5\%), matrix density (about 10\%) and higher open porosity $(12 \%$ and $5 \%)$ than reference plaster $\mathrm{P} 1$. The commercial renovation plasters $\mathrm{P} 4$ and P5 exhibited much higher differences of porosity (about 70\% and 53\%) and much lower value of bulk density (about 43\% and 30\%) and matrix density (about $30 \%$ and $20 \%$ ) with respect to reference plaster $\mathrm{P} 1$.

Table 2: $\quad$ Basic physical properties of studied plasters.

\begin{tabular}{|c|c|c|c|}
\hline \multirow{2}{*}{ Material } & $\rho$ & $\rho_{\text {mat }}$ & $\psi$ \\
\cline { 2 - 4 } & {$\left[\mathrm{kg} \mathrm{m}^{-3}\right]$} & {$\left[\mathrm{kg} \mathrm{m}^{-3}\right]$} & {$[\%]$} \\
\hline P1 & 1805 & 2879 & 28.8 \\
\hline P2 & 1741 & 2688 & 32.2 \\
\hline P3 & 1768 & 2614 & 30.1 \\
\hline P4 & 1030 & 2025 & 48.7 \\
\hline P5 & 1276 & 2277 & 44.0 \\
\hline
\end{tabular}

\subsection{Mechanical properties}

Figure 1 shows mechanical properties of five studied plasters. The addition of metakaolin to lime at the production of renovation plasters remarkably improved the compressive strength which increased up to 5.5 times compared to P1. Relatively good result was also obtained for material P2 with metashale admixture. The strengths increased up to 3 times compared to P1. The commercial plasters P4 and P5 achieved higher values of compressive strength than reference material P1. The compressive strength of P5 was also about $11 \%$ higher than for P2 with metashale admixture but significantly lower (more than 2 times) than for P3 with metakaolin admixture. Commercial plaster P4 achieved 
lower value of compressive strength compared to both plasters with pozzolanic admixtures. All studied materials had higher bending strength as compared to reference lime plaster P1. The results were similar for P2-P5, the highest value achieved commercial material P5.

\subsection{Water vapor transport properties}

Table 3 shows that water vapor diffusion properties of all studied plasters did not exhibit very high differences. The best ability of water vapor transport had reference material $\mathrm{P} 1$. In the range of lower relative humidity $\mathrm{P} 1, \mathrm{P} 2$ and $\mathrm{P} 4$ had almost the same values of water vapor diffusion coefficient. The highest $D$ values achieved P3 with metakaolin and one of the commercial renovation plasters denoted P5. This does not agree well with the porosity data in Table 2; the commercial plasters had the highest porosity. The most probable explanation could be in the specific (but not exactly known) chemical composition of commercial renovation plasters; they could contain foaming and hydrophobization additions.

The measured data revealed basic information that the values of water vapor diffusion coefficient corresponding to the lower values of relative humidity $(5 / 25 \%)$ were always lower than those for higher relative humidity values $(97 / 25 \%)$. This is in accordance with the previous measurements on many other materials including concrete. The main reason for this finding is coupling of water vapor transport with liquid water transport in a material with higher relative humidity where the capillary condensation takes place in a much higher extent than in the range of lower relative humidity [6].

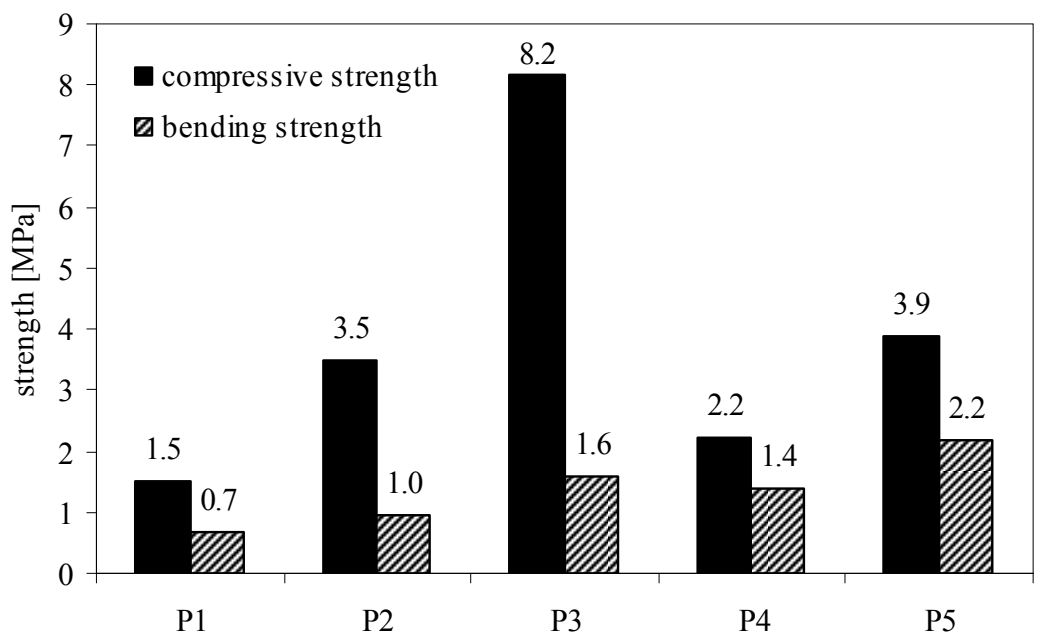

Figure 1: $\quad$ Mechanical properties of studied plasters. 
Table 3: $\quad$ Water vapor properties of the studied plasters.

\begin{tabular}{|l|l|l|l|l|l|l|}
\hline \multirow{2}{*}{$\begin{array}{l}\text { Mate } \\
\text { rial }\end{array}$} & $5 / 25-30 \%$ & \multicolumn{4}{|l|}{$97 / 25-30 \%$} & \\
\cline { 2 - 8 } & $\delta$ & $\mathrm{D}$ & $\mu$ & $\delta$ & $\mathrm{D}$ & $\mu$ \\
\cline { 2 - 8 } & {$[\mathrm{s}]$} & {$\left[\mathrm{m}^{2} \mathrm{~s}^{-1}\right]$} & {$[-]$} & {$[\mathrm{s}]$} & {$\left[\mathrm{m}^{2} \mathrm{~s}^{-1}\right]$} & {$[-]$} \\
\hline P1 & $1.02 \mathrm{E}-11$ & $1.41 \mathrm{E}-06$ & 16.4 & $5.73 \mathrm{E}-11$ & $7.88 \mathrm{E}-06$ & 3.1 \\
\hline P2 & $1.06 \mathrm{E}-11$ & $1.45 \mathrm{E}-06$ & 15.9 & $4.39 \mathrm{E}-11$ & $6.03 \mathrm{E}-06$ & 4.0 \\
\hline P3 & $6.08 \mathrm{E}-12$ & $8.35 \mathrm{E}-07$ & 30.1 & $2.98 \mathrm{E}-11$ & $4.09 \mathrm{E}-06$ & 5.7 \\
\hline P4 & $1.10 \mathrm{E}-11$ & $1.51 \mathrm{E}-06$ & 15.3 & $2.83 \mathrm{E}-11$ & $3.89 \mathrm{E}-06$ & 5.9 \\
\hline P5 & $8.33 \mathrm{E}-12$ & $1.15 \mathrm{E}-06$ & 20.4 & $3.37 \mathrm{E}-11$ & $4.63 \mathrm{E}-06$ & 5.0 \\
\hline
\end{tabular}

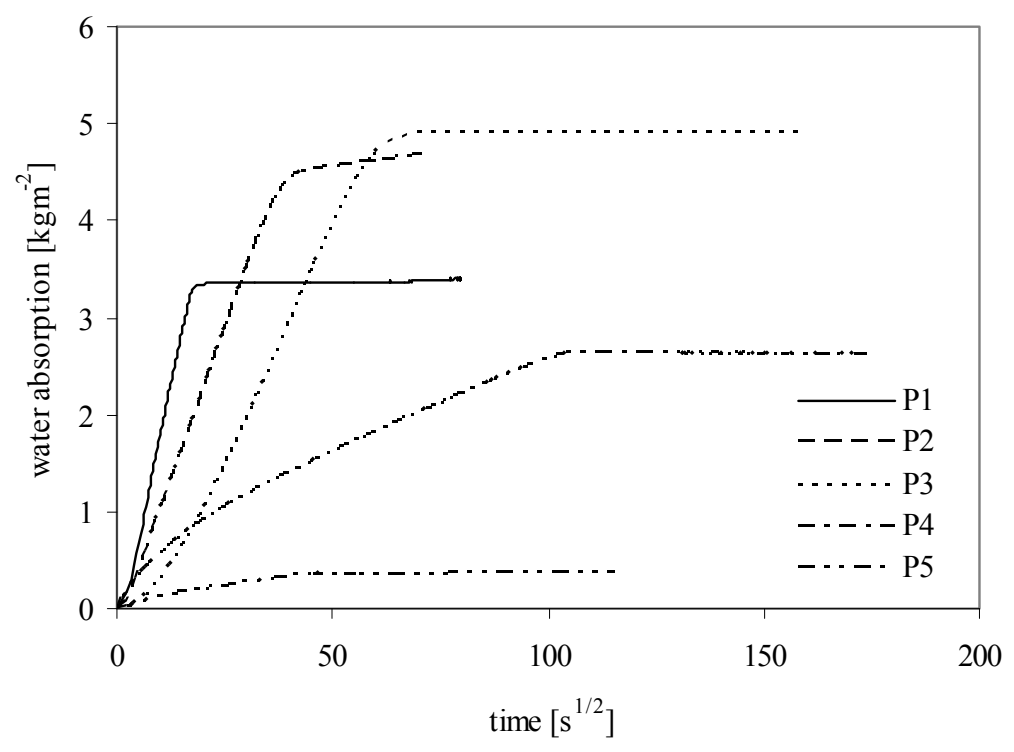

Figure 2: Water absorption of studied plasters.

\subsection{Water transport properties}

The characteristic results of water sorptivity measurements are presented in Figure 2, the calculated water transport parameters in Table 4. The water absorption coefficient $A$ of lime-pozzolana plasters $\mathrm{P} 2$ and $\mathrm{P} 3$ was lower (about $40 \%$ and 5 times, respectively) than for the reference lime plaster P1. P3 exhibited also a significantly lower $A$ value than the commercial plaster P4. The lowest value of water absorption coefficient achieved commercial plaster P5. This does not agree well with the porosity data in Table 2 . The commercial plasters P4 and P5 had the lowest values of water absorption coefficient despite their very high porosity. This was probably achieved by the application of hydrophobization additions. 
Table 4: $\quad$ Water transport properties of the studied plasters.

\begin{tabular}{|l|c|l|}
\hline \multirow{2}{*}{ Material } & \multicolumn{1}{|l|}{$\mathrm{K}$} & $\kappa$ \\
\cline { 2 - 3 } & {$\left[\mathrm{kg} \mathrm{m}^{-2} \mathrm{~s}^{-1 / 2}\right]$} & {$\left[\mathrm{m}^{2} \mathrm{~s}^{-1}\right]$} \\
\hline P1 & 0.206 & $8.80 \mathrm{E}-7$ \\
\hline P2 & 0.133 & $1.71 \mathrm{E}-7$ \\
\hline P3 & 0.040 & $1.82 \mathrm{E}-8$ \\
\hline P4 & 0.061 & $1.56 \mathrm{E}-8$ \\
\hline P5 & 0.019 & $1.88 \mathrm{E}-9$ \\
\hline
\end{tabular}

\section{Conclusions}

Experimental results presented in this paper have shown that the analyzed limepozzolana plasters were suitable for an application in reconstruction of historical buildings. Metakaolin and metashale proved to be valuable pozzolanic admixtures, with a capability to improve substantially the properties of lime plasters. While for metakaolin this could be expected as relatively wide experimental work was done within the past decade or two, metashale was not yet investigated in much detail before.

The properties of studied lime-pozzolana plasters were relatively close to commercial renovation plasters. The strength values were better or comparable, the water vapor transport properties similar, water transport parameters somewhat worse. Taking into account that this level of properties was achieved without using any special admixtures and no cement of any kind, it seems that both metakaolin and metashale would be prospective materials for use in renovation plasters.

\section{Acknowledgement}

This research has been supported by the Czech Science Foundation, under grant No 103/09/0780.

\section{References}

[1] Cabrera, J. \& Rojas, M.S., Mechanism of hydration of the metakaolin-limewater system. Cement and Concrete Research, 31, pp. 177-187, 2001.

[2] Rojas, M.S. \& Cabrera, J., The effect of temperature on the hydration rate and stability of the hydration phases of metakaolin-lime-water systems. Cement and Concrete Research, 32, pp. 133-138, 2002.

[3] Černý, R., Kunca, A., Tydlitát, V., Drchalová, J. \& Rovnaníková, P., Effect of Pozzolanic Admixtures on Mechanical, Thermal and Hygric Properties of Lime Plasters. Construction and Building Materials, 20, pp. 849-857, 2006. 
[4] Roels, S., Carmeliet, J., Hens, H., Adan, O., Brocken, H., Černý, R., Pavlík, Z., Hall, C., Kumaran, K., Pel, L. \& Plagge, R., Interlaboratory Comparison of Hygric Properties of Porous Building Materials. Journal of Thermal Envelope and Building Science, 27, pp. 307-325, 2004.

[5] Kumaran, M.K., Moisture diffusivity of building materials from water absorption measurements. Journal of Thermal Envelope and Building Science, 22, pp. 349-355, 1999.

[6] Černý, R. \& Rovnaníková, P., Transport Processes in Concrete. Spon Press: London, 2002. 